06;13

\title{
Новые оксидные покрытия \\ на монокристаллическом сапфире и спеченной керамике
}

\author{
() В.Н. Гурин, В.М. Крымов, В.В. Шпейзман, А.Б. Синани, \\ М.Ф. Киреенко, А.И. Аверкин, Л.И. Деркаченко
}

Физико-технический институт им. А.Ф. Иофрфе РАН,

Санкт-Петербург, Россия

E-mail: vladimir.gurin@mail.ioffe.ru

\section{Поступило в Редакцию 15 мая 2018 г.}

Исследовано образование оксидных защитных и упрочняющих покрытий на поверхности монокристаллического сапфира и спеченного корунда (керамики). До настоящего времени корундовые системы с оксидными покрытиями неизвестны, и наши исследования являются пионерскими. Разработаны составы покрытия на основе смеси оксидов $\mathrm{Al}_{2} \mathrm{O}_{3}+\mathrm{B}_{2} \mathrm{O}_{3}$, а также технология их нанесения на образцы. Проведено изучение прочности полученных образцов при испытаниях на изгиб. Показано, что упрочнение на отдельных образцах достигает $\sim 30 \%$, а микротвердость $\mathrm{HV}=30 \mathrm{GPa}$. На основе результатов исследования значительного количества образцов, полученных при различных условиях, сделан вывод о перспективности разработанного способа защиты и упрочнения корундовых изделий.

DOI: $10.21883 /$ PJTF.2018.19.46683.17385

Во многих случаях, например в металлургии при разливке сталей и сплавов, требуется высокая устойчивость керамических изделий (в том числе из $\left.\mathrm{Al}_{2} \mathrm{O}_{3}\right)$ к металлическим расплавам. Известны работы по защите металлических поверхностей (например, титана) оксидными покрытиями [1-3], а также по защите сапфира „неоксидными“ материалами [4]. Однако защита поверхностей оксидных изделий оксидными покрытиями неизвестна. Целью настоящей работы является поиск защитных и упрочняющих покрытий, состоящих из оксидных, но более огнеупорных компонентов. Также цель состоит в разработке технологии нанесения таких покрытий и изучении прочностных характеристик получаемых образцов. 
Ранее было найдено, что при спекании порошков оксидов $\mathrm{Al}_{2} \mathrm{O}_{3}$ и $\mathrm{B}_{2} \mathrm{O}_{3}$ (иногда с добавлением элементарного бора) на поверхности спрессованного порошка корунда во всех экспериментах образовывались высокотвердые соединения $10 \mathrm{Al}_{2} \mathrm{O}_{3}+2 \mathrm{~B}_{2} \mathrm{O}_{3}\left(\mathrm{Al}_{20} \mathrm{~B}_{4} \mathrm{O}_{36}\right)$ или сокращенно $\mathrm{Al}_{5} \mathrm{BO}_{9}$, а также субоксид $\mathrm{B}_{6} \mathrm{O}[5,6]$. Все эксперименты проводились путем искрового плазменного спекания на установке СПАРК-ПЛАЗМА с использованием пульсирующего электроразряда с одновременным давлением (сжатием образца из прессованного порошка корунда). Согласно фазовой диаграмме $\mathrm{Al}_{2} \mathrm{O}_{3}-\mathrm{B}_{2} \mathrm{O}_{3}[7,8]$, приведенной на рисунке, в системе образуются два соединения - так называемые бороалюминаты:

1) $2 \mathrm{Al}_{2} \mathrm{O}_{3}+\mathrm{B}_{2} \mathrm{O}_{3}\left(\mathrm{Al}_{4} \mathrm{~B}_{2} \mathrm{O}_{9}\right)$ с $T_{m}=1150^{\circ} \mathrm{C}$ [7] $\left(1180^{\circ} \mathrm{C}\right.$ по данным $[8]$;

2) $9 \mathrm{Al}_{2} \mathrm{O}_{3}+\mathrm{B}_{2} \mathrm{O}_{3} \quad\left(\mathrm{Al}_{18} \mathrm{~B}_{4} \mathrm{O}_{33}\right)$ с $T_{m}=1440^{\circ} \mathrm{C} \quad$ [7] $\quad\left(1930^{\circ} \mathrm{C}\right.$ по данным $[8])$.

По измерениям, проведенным в [5] на Camebax, существует третье соединение с формулой $\mathrm{Al}_{2} \mathrm{O}_{3}+9 \mathrm{Al}_{2} \mathrm{O}_{3} \cdot 2 \mathrm{~B}_{2} \mathrm{O}_{3}\left(\mathrm{Al}_{20} \mathrm{~B}_{4} \mathrm{O}_{36}\right)$. В [7] $T_{m}$ для него не указана, а в [8] сведения об этом соединении отсутствуют.

Все указанные выше бороалюминаты являются недостаточно изученными, для них практически отсутствуют термодинамические данные (свободная энергия, теплота образования и др.), а одна из упомянутых фазовых диаграмм системы $\mathrm{Al}_{2} \mathrm{O}_{3}-\mathrm{B}_{2} \mathrm{O}_{3}$ является расчетной [7].

Как показали предыдущие исследования, самым прочным и тугоплавким соединением из приведенных выше является бороалюминат состава $\mathrm{Al}_{20} \mathrm{~B}_{4} \mathrm{O}_{36}\left(\mathrm{Al}_{5} \mathrm{BO}_{9}\right)$. Он образуется при высоких температурах, и его микротвердость $\mathrm{HV}$ достигает $30 \mathrm{GPa}[5,6])$. Субоксид бора $\mathrm{B}_{6} \mathrm{O}$ всегда присутствует в небольших количествах в виде субмикронных поликристаллов, не образует сплошных областей и для покрытий непригоден.

В настоящей работе оксидные покрытия получались в обычных условиях высокотемпературного прожига в атмосфере аргона. Использовались различные формы образцов и составы исходных покрытий. Керамические образцы для испытаний вырезались на станке алмазной резки „Алмаз-4“ из пластины размером $50 \times 50 \times 5 \mathrm{~mm}$. Образцы монокристаллического сапфира вырезались из стержней квадратного сечения $5 \times 5 \mathrm{~mm}$, выращенных методом Степанова. Таким образом были получены образцы в форме тонких пластинок размером $25 \times 5 \times 1 \mathrm{~mm}$.

Письма в ЖТФ, 2018, том 44, вып. 19 


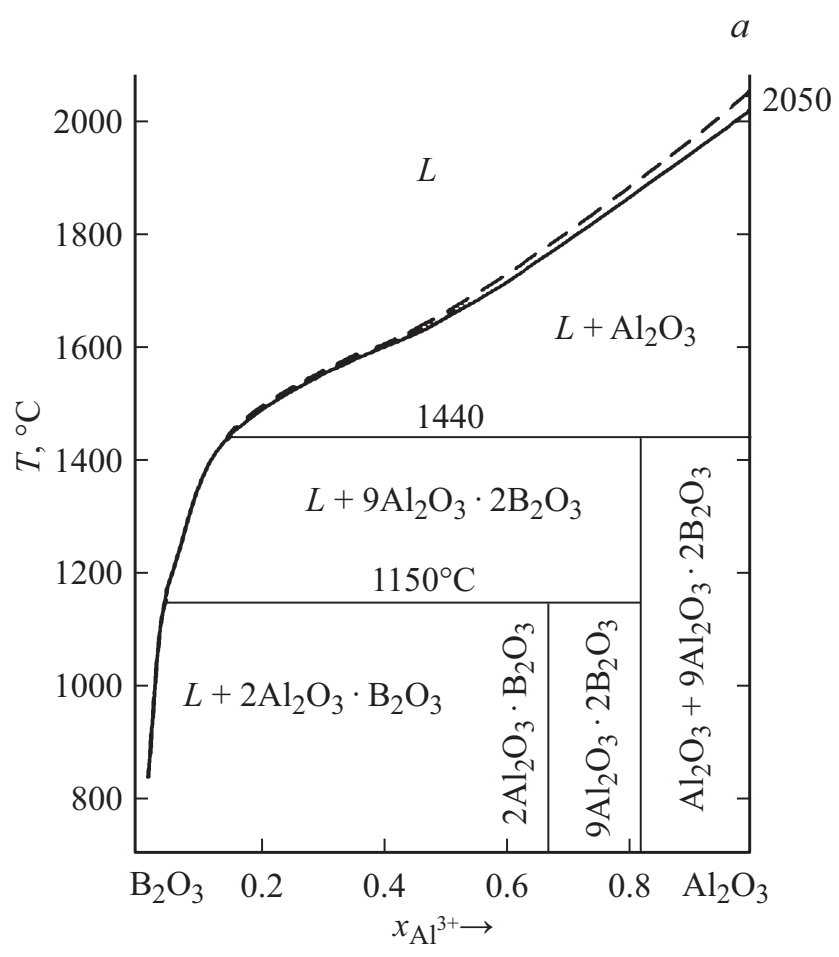

Фазовые диаграммы системы $\mathrm{Al}_{2} \mathrm{O}_{3}-\mathrm{B}_{2} \mathrm{O}_{3}$ по данным различных источников: $a-[7], b-[8]$.

Были приготовлены составы, соответствующие фазовой диаграмме, которые наносились на одну сторону пластин из спеченной керамики и монокристаллического сапфира, которая в дальнейшем подвергалась растягивающим напряжениям при изгибе. Способ нанесения является авторским „ноу-хау“. После просушивания образцы помещались в вакуумную печь и нагревались в атмосфере аргона до необходимой температуры (как правило, на $10-50^{\circ} \mathrm{C}$ выше точки плавления на фазовой диаграмме для той фазы, состав которой был нанесен на пластину, т.е. до $\left.\sim 1400-1600^{\circ} \mathrm{C}\right)$, выдерживались в течение $4 \mathrm{~h}$ при этой температуре и охлаждались также $4 \mathrm{~h}$. В результате на пластинах образовывались тонкие покрытия того или иного состава в зависимости

Письма в ЖТФ, 2018, том 44, вып. 19 


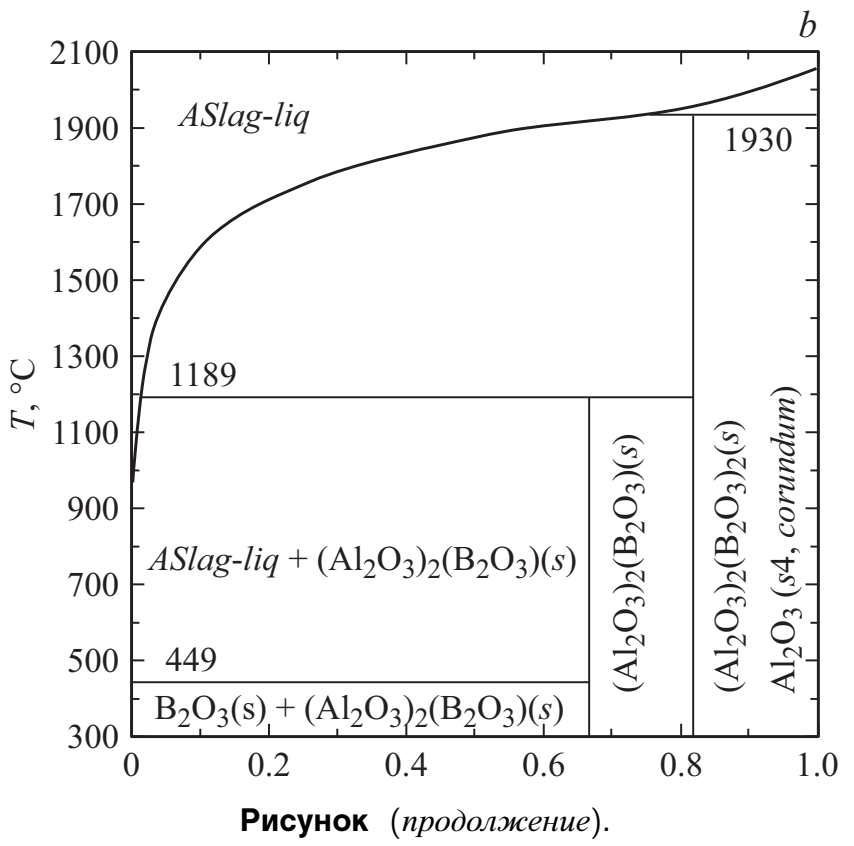

от взятой исходной смеси. На основе фазовых диаграмм и с учетом результатов анализа на Camebax [5] были выбраны два пути образования наиболее прочного и тугоплавкого соединения $\mathrm{Al}_{20} \mathrm{~B}_{4} \mathrm{O}_{36}$ в качестве покрытия.

Путь I - с использованием элементарного бора: $12 \mathrm{Al}_{2} \mathrm{O}_{3}+12 \mathrm{~B}=$ $=\mathrm{Al}_{20} \mathrm{~B}_{4} \mathrm{O}_{36}+4 \mathrm{AlB}_{2}$

Путь II - с использованием оксида бора: $10 \mathrm{Al}_{2} \mathrm{O}_{3}+2 \mathrm{~B}_{2} \mathrm{O}_{3}=$ $=\mathrm{Al}_{20} \mathrm{~B}_{4} \mathrm{O}_{36}$

Следует отметить, что путь I протекает с образованием побочного соединения - $\mathrm{AlB}_{2}$ (диборида алюминия), легкоплавкого и низкопрочного. Полученные результаты зависят от различных условий технологии, которые могут меняться от опыта к опыту, что затрудняет объективную оценку результатов. Такими условиями в первую очередь являются температурно-временны́е условия эксперимента, а также состав покрытий, наносимых на поверхность образцов, толщина наносимого слоя, поверхностная пористость, наличие примесей, способ 
нанесения, скрепляющий компонент в исходном покрытии, крепление образцов в печи и др. Важное значение имеет также исходное состояние поверхности образца (в идеале полированная поверхность), а для кристаллических образцов - кристаллографическая ориентация образца. В наших опытах покрываемая поверхность совпадала с плоскостью основания гексагональной призмы.

Как следует из фазовой диаграммы системы $\mathrm{Al}_{2} \mathrm{O}_{3}-\mathrm{B}_{2} \mathrm{O}_{3}$ (см. рисунок, $a, b)$, фазы $\mathrm{Al}_{4} \mathrm{~B}_{2} \mathrm{O}_{9}$ и $\mathrm{Al}_{18} \mathrm{~B}_{4} \mathrm{O}_{33}$ имеют $T_{m}$, более низкую на диаграмме $a$, чем на диаграмме $b$ (на 39 и $490^{\circ} \mathrm{C}$ соответственно). Это затрудняет выбор оптимальной температуры прожига, причем экспериментально установленное нами ранее [5] соединение $\mathrm{Al}_{20} \mathrm{~B}_{4} \mathrm{O}_{36}$ $\left(\mathrm{Al}_{5} \mathrm{BO}_{9}\right)$ на диаграммах не указано. Это может быть связано с недостаточной изученностью системы, например с отсутствием сведений о существовании не указанных на диаграмме твердых растворов, в частности $\mathrm{Al}_{20} \mathrm{~B}_{4} \mathrm{O}_{36}\left(\mathrm{Al}_{5} \mathrm{BO}_{9}\right)$.

Прочность полученных образцов определялась в испытаниях на трехточечный изгиб при комнатной температуре на универсальной испытательной машине Instron 1342. Максимальные напряжения $\sigma$ рассчитывались по формуле $\sigma=M / W$, где $M$ - максимальный изгибающий момент, а $W$ - сопротивление изгибу, которое для прямоугольного сечения образца равно $W=b h^{2} / 6(b-$ ширина, $h$ - толщина образца). Расстояние между опорами составляло $20 \mathrm{~mm}$, скорость движения подвижного захвата машины $-5 \mu \mathrm{m} / \mathrm{s}$. Поверхность образца с покрытием находилась на противоположной по отношению к приложенной силе стороне, т. е. в зоне растягивающих напряжений.

Была измерена прочность на изгиб в различных сериях экспериментов. Во всех случаях исследовались и сравнивались керамические образцы, полученные высокотемпературным спеканием, и образцы, вырезанные из монокристаллов сапфира.

В табл. 1 представлены результаты измерения прочности при изгибе для обоих путей образования упрочняющих покрытий на поверхности кристаллического сапфира и прессованной керамики. Испытания показали, что покрытия на монокристаллическом сапфире практически всегда приводят к большему упрочнению, чем на прессованной керамике. На основе полученных данных можно определенно заключить, что предлагаемые покрытия упрочняют кристаллический сапфир и керамику, при этом путь II (смесь оксидов) является более дешевым и доступным. В то же время следует отметить, что важную роль в

Письма в ЖТФ, 2018, том 44, вып. 19 
Таблица 1. Прочность на изгиб $\sigma$ образцов керамики и сапфира: исходных и с покрытием, содержащим бор (каждое из значений получено в результате четырех измерений)

\begin{tabular}{l|r|r}
\hline \multirow{2}{*}{ Образец } & \multicolumn{2}{|c}{$\sigma, \mathrm{MPa}$} \\
\cline { 2 - 3 } & Керамика & \multicolumn{1}{|c}{ Сапфир } \\
\hline Исходный, без покрытия & $420 \pm 53$ & $851 \pm 83$ \\
С покрытием & $446 \pm 31$ & $1082 \pm 44$
\end{tabular}

Таблица 2. Микротвердость (HV) полированных (без покрытия) и неполированных образцов с односторонним покрытием, содержащим бор (нагрузка $200 \mathrm{~g}$, каждое из значений получено в результате 24 измерений)

\begin{tabular}{l|c||l|c}
\hline \multicolumn{1}{c||}{ Керамика } & $\mathrm{HV}, \mathrm{GPa}$ & \multicolumn{1}{c|}{ Сапфир } & $\mathrm{HV}, \mathrm{GPa}$ \\
\hline $\begin{array}{l}\text { Полированный } \\
\text { образец }\end{array}$ & $18.6 \pm 1.3$ & $\begin{array}{l}\text { Полированный } \\
\text { образец }\end{array}$ & $18.6 \pm 2.2$ \\
С покрытием & $29.2 \pm 4.7$ & С покрытием & $17.9 \pm 4.1$
\end{tabular}

упрочнении играет равномерное распределение как исходного, так и прореагировавшего покрытия на поверхности образца, в особенности при повышении температуры процесса до $1600^{\circ} \mathrm{C}$. При сравнении результатов следует учитывать также толщину покрытия (что требует дополнительных исследований), а также наличие в образце микротрещин и областей высоких локальных напряжений (последствия резки образцов).

Было изучено также влияние полированной поверхности сапфира и керамики на изменение прочности на изгиб и микротвердости в сравнении с обычными нарезанными образцами. Как показали исследования (табл. 2), полировка образцов перед нанесением покрытия не привела к существенному упрочнению по сравнению с обычными необработанными образцами. При этом полированный образец сапфира практически не отличался от керамики, а керамика с покрытием показала в последних экспериментах даже более высокие значения $\sigma$, чем монокристаллический сапфир. Это связано с большей неравномерностью распределения покрытия на полированных образцах. Было установле-

Письма в ЖТФ, 2018, том 44, вып. 19 
но, что на полированном образце покрытие после соответствующего прожига неравномерно распределяется по полированной поверхности, образуя небольшие (десятки микрометров) участки-,кучки“, которые показывают значительно более высокую микротвердость, чем соседние области на образце (можно добавить, что такая же картина, но в меньшей степени иногда наблюдалась и на неполированных образцах). Это подтверждает факт образования покрытия, содержащего твердые вещества - бороалюминаты и, в частности, $\mathrm{Al}_{20} \mathrm{~B}_{4} \mathrm{O}_{36}$. K сожалению, в условиях эксперимента нет возможности установить состав этих „кучек“. Наличие таких различных участков требует использования добавок к покрытиям, которые улучшат смачиваемость поверхности образцов и обеспечат более равномерное распределение покрытия на их поверхности.

Таким образом, несмотря на то что не было проведено определение количества бороалюмината в покрытии и не был выбран его оптимальный состав, удалось упрочнить изделие на $\sim 30 \%$, что само по себе является важным результатом, как и приоритет в разработке нового оксидного покрытия на монокристаллическом сапфире и спеченной керамике.

\section{Список литературы}

[1] Фомин А.А., Штейнгауэр А.Б., Лясников В.Н., Вениг С.Б., Захаревич А.М. // Письма в ЖТФ. 2012. Т. 38. В. 10. С. 64-69.

[2] Фомин А.А., Штейнгауэр А.Б., Родионов И.В., Фомина М.А., Захаревич А.М. // Письма в ЖТФ. 2013. Т. 39. В. 21. С. 70-75.

[3] Фомин А.А., Фомина М.А., Родионов И.В., Кошуро В.А., Пошивалова Е.Ю., Щелкунов А.Ю., Скапцов А.А., Захаревич А.М., Аткин В.С. // Письма в ЖТФ. 2015. Т. 41. В. 18. С. 89-95.

[4] Гурин В.Н., Синани А.Б., Деркаченко Л.И., Трунов В.А., Зайщев Г.П., Крымов В.М. // Новые огнеупоры. 2008. № 8. С. 47-52.

[5] Гурин В.Н., Гринь Ю., Костманн С., Мейер К., Деркаченко Л.И. // Новые огнеупоры. 2015. № 1. С. 35-38.

[6] Гурин В.Н. // Сб. материалов XXIII Петербургских чтений по проблемам прочности, посвященных 100-летию ФТИ им. А.Ф. Иоффе и 110-летию чл.-корр. АН СССР А.В. Степанова. СПб.: Изд-во ВВМ, 2018. С. 61-63.

[7] Михайлов Г.Г., Макровеи, Л.А., Смирнов Л.А. // Вестн. ЮУрГУ. Сер. Металлургия. 2014. Т. 14. № 4. С. 11-16.

[8] Fact Sage. Sistems $\mathrm{Al}_{2} \mathrm{O}_{3}-\mathrm{B}_{2} \mathrm{O}_{3}$.

5 Письма в ЖТФ, 2018, том 44, вып. 19 